\title{
Downes, Stephanie; Lynch, Andrew; O'Loughlin, Katrina (eds.) (2018), Writing War in Britain and in France, 1370-1854. A History of Emotions, Routledge, London \& New York, 258 págs. ISBN: 978-11-3821-916-8.
}

La historia de las emociones ha protagonizado un espectacular desarrollo desde el cambio de milenio, teniendo un especial arraigo en la historiografía anglosajona. Esta disciplina cuenta ya con renombrados especialistas, numerosas publicaciones e incluso centros de investigación dedicados íntegramente a su estudio en Londres, Berlín o Sidney. Precisamente al amparo de la institución australiana realiza sus labores de investigación el grupo que ha hecho posible este libro. Por su parte, el estudio de la cultura escrita ha gozado también de un gran desarrollo entre los investigadores europeos, pudiendo destacar nombres como los de Roger Chartier o Fernando Bouza.

La obra presenta trabajos centrados en una forma concreta de expresión de emociones y sentimientos, la escrita, desarrollada en un contexto histórico muy determinado, el de la guerra. Es un tema, el de los desastres de la guerra y cómo afectan al individuo, ya tratado por algunos de los autores que participan en este volumen, pero también cuenta con otros precedentes como Un tiempo de guerra de Lauro Martines, si bien no se centra tanto en la plasmación de sentimientos en la cultura escrita; también investigadores españoles se han acercado a este aspecto, como es el caso de David García Hernán y su obra La cultura de la guerra y el teatro en el Siglo de Oro.

Juntando especialistas en estudios medievales, modernistas y románticos Writing War in Britain and in France presenta las distintas formas de escribir la guerra de una forma "transhistórica", a lo largo de cinco siglos; transnacional, en Gran Bretaña y en Francia; y a través de distintos géneros literarios, desde cartas privadas hasta producciones literarias y teatrales. Su objetivo es analizar, en un amplio rango cronológico, la historia de los sentimientos producidos por la guerra en relación con la naturaleza cambiante de los conflictos y los modos de escritura, la evolución de su plasmación en los diferentes tipos de textos y cómo la escritura ha ayudado a conformar la guerra en tanto experiencia emocional. Para ello dedica diversos ensayos, en un acertado orden cronológico, a cada una de las épocas mencionadas (Edad Media, Edad Moderna y siglo XIX), en los que los investigadores analizan textos de esas cronologías explicando su contexto de producción, los objetivos que persiguen y qué sentimientos y emociones pueden apreciarse en esos registros. 
Tras unas páginas de introducción a los objetivos de la obra y de presentación de la misma, los primeros capítulos están dedicados a la literatura bélica de los siglos bajomedievales. Los autores de esta cronología muestran cómo existía una realidad bien distinta a la que encontramos en los siglos posteriores que se tratan en el propio libro, con ausencia de narraciones en primera persona de esas experiencias, práctica inexistencia de correspondencia y de diarios de guerra. La plasmación de sentimientos hay que encontrarla, por lo tanto, en obras escritas en tercera persona, como puedan ser las abundantes crónicas producidas en las últimas centurias medievales y aquí analizadas.

En una cultura escrita en la que aún tenían mucho peso los libros de caballerías medievales, Craig Taylor, Andrew Lynch, Tracy Adams y Catherine Nall muestran que la expresión de las emociones no era todavía un objetivo, sino un medio para alcanzar otras metas. Además, el rango de sentimientos que se puede apreciar es mucho más limitado que en momentos posteriores. Esa emotividad introducida en los textos perseguía dos posibles resultados: bien, en una narración muy centrada en las acciones, mostrar cómo las emociones conducen a ellas y así subrayarlas y justificarlas (por ejemplo, el enfado, la rabia o el dolor como antesala de la venganza); bien, buscar un cierto carácter aleccionador que provocara la reflexión del lector (por ejemplo, enfrentando violencia con fuerza justa o ira y piedad, jugando un papel fundamental en las reflexiones sobre guerra justa).

Con la llegada de la Edad Moderna se generalizaron también nuevas prácticas de escritura: publicaciones de noticias (preperiódicas, en un primer momento, y periódicas, más adelante); literatura destinada a un público amplio (teatro, prosa y poesía); o intercambios epistolares. Sobre estos nuevos géneros y su relación con los sentimientos ocasionados por los conflictos bélicos es sobre lo que trata el grueso de los capítulos de la obra.

Los distintos investigadores modernistas que participan en la publicación muestran cómo en esta época ya existió una preocupación por mostrar y provocar, por ver y leer, emociones; haciéndolo, además, de una forma explícita y directa. Muestran diversos ejemplos a este respecto, como el caso del autor inglés Thomas Dekker, estudiado por Merridee Bailey, que dedicó buena parte de su producción a mostrar los negativos efectos que tenía la guerra en los ciudadanos ordinarios, desde el impacto económico hasta la angustia por la pérdida de seres queridos o las secuelas emocionales de los soldados que regresan.

Unos sentimientos similares se pueden apreciar en las cartas intercambiadas entre Enrique II y Catalina de Médicis y estudiadas por Susan Broomhall, en las que se plasma la preocupación de la reina por la salud de su marido, además de la devoción y el agradecimiento de éste por la labor que desempeñó su mujer como regente en su ausencia. La misma intención de influir en el lector que se apreciaba en los escritos de Dekker se puede percibir en la publicística y los panfletos producidos en torno a la Guerra de los Obispos, según explica Gordon Raeburn. Mediante esos textos los escoceses trataron de mostrar a la población inglesa, 
mediante unos escritos dominados por los sentimientos, que no tenían otra alternativa que la respuesta armada, pero tratando de establecer vínculos de amistad proponiendo una unión contra Carlos I. Igualmente, tras la batalla de Newburn, intentaron tranquilizar a la población haciendo ver que no eran una fuerza invasora.

Las novedades con respecto al siglo XIX, un salto cronológico amplio, pues ningún autor trata la Ilustración, son mucho menores que las que se pudieron apreciar con respecto a la Edad Media. Los usos y los medios eran similares, salvando la creciente importancia que tuvieron las publicaciones periódicas, si bien en el Romanticismo existió una cierta tendencia a la conmemoración de conflictos bélicos, como ejemplifica Robert White con el caso de la batalla de Waterloo. Además, como parte de esa recepción de guerras pasadas se puso especial interés en el sufrimiento individual de los soldados y su experiencia personal, llegando a aparecer literatura especializada en eso, como el United Service Journal sobre el que trata Neil Ramsey.

El lector de esta ambiciosa obra, al concluirla, tendrá la sensación de una mayor cercanía a las distintas sociedades tratadas en la misma y a los efectos, siempre fatales, que las distintas guerras tuvieron en la población. Un objetivo fundamental de la historia de las emociones, disciplina a la que este estudio contribuye de una forma notable. El libro, gracias a la amplitud cronológica que plantea, permite apreciar la evolución tanto de las formas de escribir sobre los conflictos y la manera en que estos afectaron, como del interés y las intenciones a la hora de expresar sentimientos y emociones; lo cual es, posiblemente, la mayor virtud de la investigación.

Álvaro Bueno Blanco 